\title{
QUICK LOOK REPORT ON THE STARTUP TESTS FOR THE RAFT RIVER 5MW(e) PILOT GEOTHERMAL POWER PLANT
}

\author{
EGG-GTH--5716 \\ DE82 010612
}

C. J. BTiem

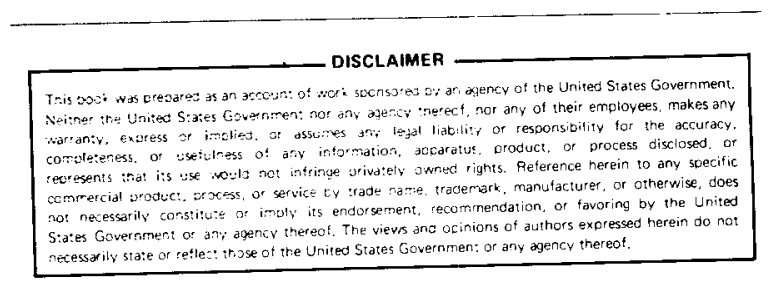

December 1981 


\section{DISCLAIMER}

This report was prepared as an account of work sponsored by an agency of the United States Government. Neither the United States Government nor any agency Thereof, nor any of their employees, makes any warranty, express or implied, or assumes any legal liability or responsibility for the accuracy, completeness, or usefulness of any information, apparatus, product, or process disclosed, or represents that its use would not infringe privately owned rights. Reference herein to any specific commercial product, process, or service by trade name, trademark, manufacturer, or otherwise does not necessarily constitute or imply its endorsement, recommendation, or favoring by the United States Government or any agency thereof. The views and opinions of authors expressed herein do not necessarily state or reflect those of the United States Government or any agency thereof. 


\section{DISCLAIMER}

Portions of this document may be illegible in electronic image products. Images are produced from the best available original document. 


\section{ABSTRACT}

A preliminary analysis was made of the initial startup data taken between October 20 and November 2, 1981 for the 5MW(e) Pilot Geothermal Power Plant located at the Raft River site in southeast Idaho. This plant utilizes a dual-boiling isobutane binary cycle. Two test conditions were selected for analysis: (1) a thermal loop test with 94\% of the design geofluid flow, and (2) a test at about three-fourths of the design geofluid flow in which one megawatt was generated from working-fluid flow through the low-pressure stage of the turbine.

Component and system energy balances were made, and comparisons between experimental results and computer simulations of the plant were conducted. A preliminary analysis of condenser tube wall temperatures was performed. Except for a malfunction in the high pressure turbine throttle valve system, the plant performed generally as predicted, and the testing was judged to be successful. 
ABSTRACT . . . . . . . . . . . . . . . . . . . . i i

1.0 INTRODUCTION AND SUMMARY . . . . . . . . . . . . . . . . . . 1

1.1. 5MW Pilot Plant Startup . . . . . . . . . . . . . . 1

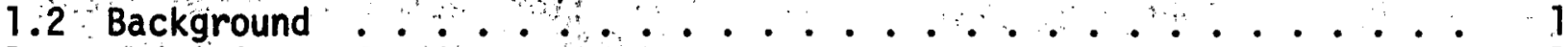

1.3 Objectives of Quick Look Report . . . . . . . . . . . . . . . . 1

1.4 Results and Conclusions . . . . . . . . . . . . . . . 2

2.0 HIGH GEOFLUID FLOW RATE TEST EVALUATION $\ldots \ldots \ldots$

2.1 Basic Data Analysis . . . . . . . . . . . . . . 4

2.2 Comparison of Data with Computer Simulation . . . . . . . . 8

3.0 POWER GENERATION . . . . . . . . . . . . . . . . . . . . . 9

4.0 DETAILED HEAT EXCHANGER DATA $. . . . . . \quad . . . . . . . . . . .11$

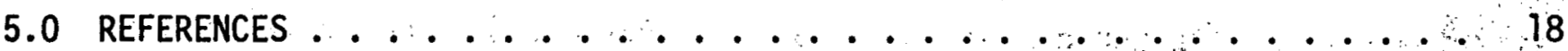

FIGURES

1. Schematic Diagram of the 5MW(e) Pilot Geothermal Power Plant . . . . . 5

2. Location of Instrumented Tubes in Condenser . . . . . . . . . . . 14

3. Condenser Tube Wall Temperatures Compared with Experimental Data . . . 15

4. Condenser Tube Wall Temperatures with Adjusted Condensing

Temperature

\section{TABLES}

1. "Best Estimate" Experimental Válues for Energy Balances . . . . . . . 6

2. Component Heat Balances using Best Estimate Experimental Values . . . 7

3. System Energy Balances . . . . . . . . . . . . . . . . 8

4. Comparison of Simulation and Experimental Measurements for High Geofluid Flow Test .................. . . 10

5. Comparison of Simulation and Experimental Measurements for Power Production Test 


\subsection{INTRODUCTION AND SUMMARY}

\subsection{MW Pilot Plant Startup}

System startup testing of the Raft River 5MW(e) Pilot Geothermal Power Plant was done between October 20 and November 2, 1981. The plant was run for two periods (October 20 through October 23 and October 28 through November 2). These tests culminated with a test in which the plant was run as a thermal loop with 94 percent of design geofluid flow and one in which the low pressure stage of the turbine generated one megawatt of electrical power with a lower geofluid flow. During this test period all components of the system were checked out. The only significant component which did not function was the throttle valve and its control system on the high pressure turbine stage. For this reason the high pressure stage could not be loaded during the power production test.

\subsection{Background}

The primary purpose of this testing was to check out the system and its individual components. The engineering performance tests are scheduled to follow in the spring and summer of 1982. Total instrumentation checkout was not a prime concern for this test phase; instrumentation was checked out to the extent that safe operation of the plant was assured. A large fraction of the instruments necessary for performance determination did not function properly during this test period; some did not function at all and others obviously read incorrectly.

There was sufficient data, however, to estimate certain performance criteria. Therefore, an analysis of the existing data was undertaken; the results of that study are presented in this report. Because this was a "quick look" at the data, some questions remain unanswered. A "best estimate" of the measured values was used, and consistency of mass and energy balances explored. No attempt has been made to check data point-by-point.

\subsection{Objectives of Quick Look Report}

The objectives of this study were: (1) to verify that all of the equipment was operating as expected, (2) to evaluate the performance information available, 
and (3) to prepare for the extensive engineering performance tests. These objectives were achieved. Component and system performance were compared to predictions for two cases. The adequacy of the instrumentation calibrations was also investigated in preparation for future tests.

These objectives were met by analyzing the High Geofluid Flow Rate Test quite extensively, and the Power Generation Test to a lesser extent. The High Geofluid Flow Rate Test was a test where the system was run as a thermal loop for approximately two hours. Eight complete sets of data are available for the last hour of this test. It was felt that this was the best set of data to analyze completely because the system was near its design point, and a complete data set existed for a reasonably long period of time:

The second operating point which was analyzed was the Power Production Phase. Unfortunately, a complete data set is not available for this time period, but the operator's data $\log$ gives some information before and after the power production. From this information a projection of maximum power produced by the low pressure tube stage was made.

\subsection{Results and Conclusions}

The major conclusions of this report are:

1. The system and individual pieces of equipment appear to be operating as original predictions indicated.

2. Although individual measurements showed fairly wide discrepancies, a set of consistent measurements could be derived from the larger data set which appeared adequate for a first analysis.

3. Energy balances performed on the heat exchangers and the system as a whole were found to have discrepancies in the order of 5 to 10 percent of the average rate of energy transferred. This result is not inconsistent with the present uncertainty in the individual measurements.

4. Comparison of the High Geofluid Flow Rate Test with a digital simulation of the system indicated that the system performance was as expected 
and that the fouling level in the geothermal heat exchangers was approximately 10 percent of the design value. That simulation suggested that fouling in the condenser may be as high as 130 percent of the design value on the cooling water side and 10 percent on the isobutane side. A detailed look at the condenser shows possibly conflicting evidence, however.

5. The computer simulation predicts that the low pressure side of the turbine is capable of producing slightly more than one megawatt output. This is in general agreement with the power produced during these tests.

6. The data from the instrumented heat exchangers appears to be generally good.

7. A look at the detailed condenser tube wall data shows that the fouling in the condenser may be near the design value (in contrast to the results from the simulation of the High Geofluid Flow Rate Test (see Conclusion 4)). A closer look at this data shows that predicted fouling is quite sensitive to condensing temperatures and cooling water inlet and outlet temperatures. At this point, the condenser fouling must be considered unresolved and the subject of further analysis.

8. Before the Engineering Performance Tests are run, additional work is needed on the instrumentation. The instruments which are not working should be repaired, and additional calibration and consistency checks are needed so that data, which will confirm performance, will be obtainable.

\subsection{HIGH GEOFLUID FLOW RATE TEST EVALUATION}

The High Geofluid Flow Rate Test affords the best opportunity to establish the plant performance. It was during this time that the plant was operating nearest its design point. All major components except for the turbine were functioning during this test, and a relatively large amount of data was available; therefore, the most extensive analysis was done using this data. 
Eight sets of complete data were taken over the time span of one hour.: The variation of all important values during this time was quite smal1. Therefore, the average measurements over this time interval were taken as the steady-state values.

Figure 1 shows a schematic of the $5 \mathrm{MW}(\mathrm{e})$ plant with various state points numbered. " Rather than use instrumental numbers, the state point numbers will be used throughout this report. At certain points there are redundant instruments. Ali values which were deemed to be functioning correctly are reported al though there is disagreement among many measurements.

Two separate analyses were made of this data. First, the experimental data alone was considered. Certain redundant measurements were ignored, others were averaged, and heat balances were made for the system and individual components. Because of the rather large uncertainties in the data, it was decided not to attempt heat transfer calculations directly. A second method of analysis, which circumvents these difficulties to a large extent, was used. The second method consists of taking the existing digital computer simulation of the plant (described in Reference 1) with the boundary conditions dictated by the test data, and predicting the fouling in the heat exchangers and system temperatures, pressures, and flows.

\subsection{Basic Data Analysis}

Table 1 gives the "best estimate" values of the measurements which are used in the energy balances. The state point numbers refer to Figure 1. For the geofluid data, the mass flow rate was taken as the averages of the two experimental measurements. The same procedure was used for all but the two lowest temperatures. For those temperatures, the lower measurement gave more consistent results. There was no redundancy in measurements for the cooling water so the individual measurements were used. In the isobutane loop, the liquid flow rates into the boilers were taken as the best working fluid flow rate measurements. These were used together with the preheater inlet flows to determine a consistent set of isobutane flows. The fact that the high preheater inlet flow was approximately equal to the high boiler inlet flow indicates no bypass around that preheater. Using the measurements for low preheater inlet flow (along with the boiler inlet 

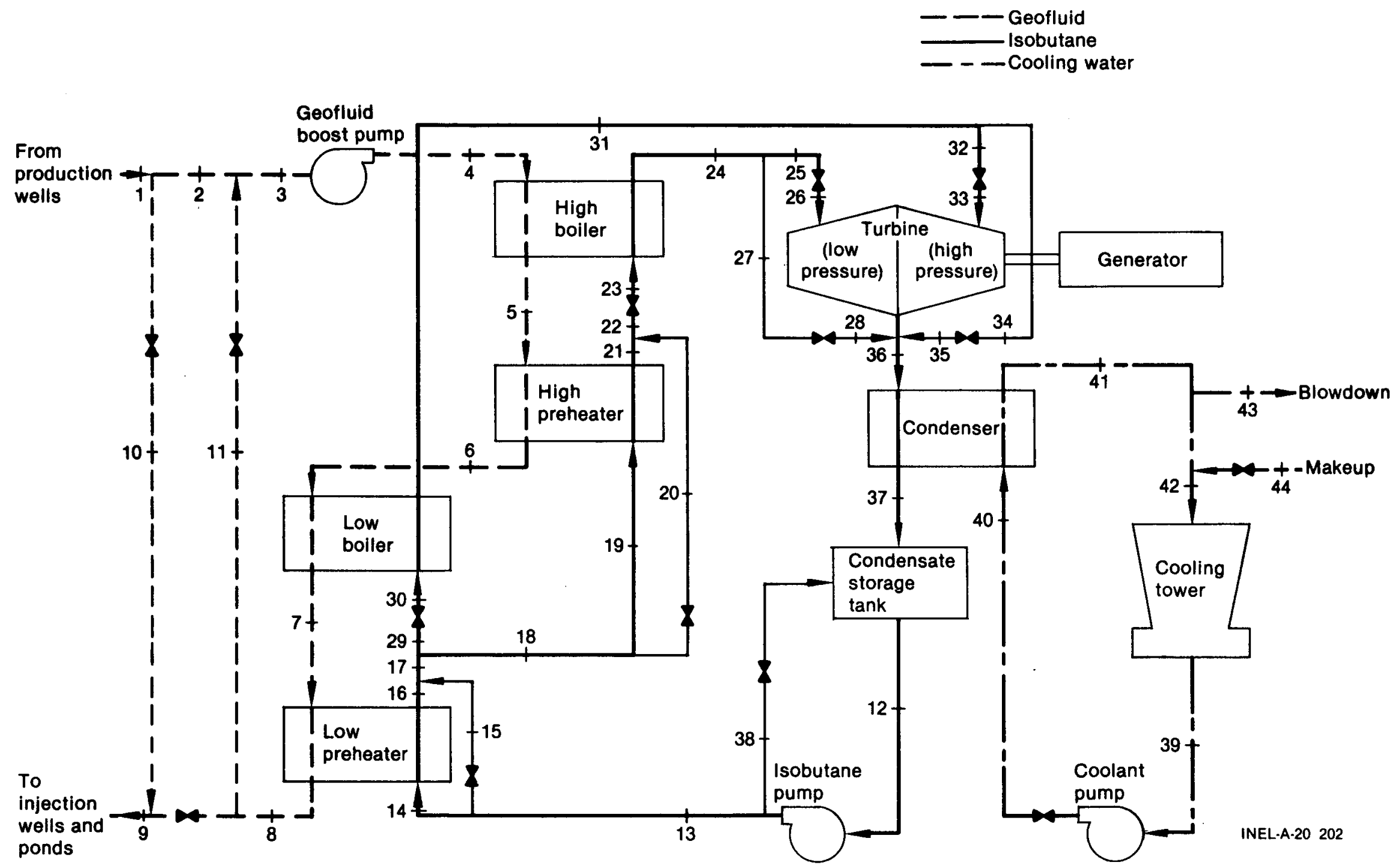

Figure 1: Schematic Diagram of the 5MW(e) Pilot Geothermal Power Plant 
TABLE 1 - "BEST ESTIMATE" EXPERIMENTAL VALVES FOR ENERGY BALANCES

State Point "Best Estimate"
Value

\section{Geofluid}

Mass Flow Rate

$\left(1 \mathrm{~b} / \mathrm{hr} \times 10^{-6}\right)$

Temperature $\left({ }^{\circ} \mathrm{F}\right)$
2
8

4

5

6

8

Cooling Water

Mass Flow Rate

$\left(1 \mathrm{~b} / \mathrm{hr} \times 10^{-6}\right)$

Temperature $\left({ }^{\circ} \mathrm{F}\right)$
40

40

41
.9786

.9786

281.6

238.8

209.8

178.3

136.4
.9923

.9649

$280.1,283.2$

$240.3,237.3$

$209.0,210.7$

$178.3,186.1$

$136.4,139.4$

\section{Isobutane}

Mass Flow Rate

$\left(1 \mathrm{~b} / \mathrm{hr} \times 10^{-6}\right)$

13

14

29

19

22

3.1

Temperature $\left({ }^{\circ} \mathrm{F}\right)$

13
14

18,29

21,22

36

37

Pressure (psig)
24

31
.8705

.8114

.3045

.5660

.5660

.3045

97.4

180.7

171.4

235.8

168.4

93.5

$336.7 *$

$180.7 *$

$58.4 *$
6.230

65.1

87.4
.9361

.8114

.3045

.5661

.5659

.2661

$97.5,97.3$

180.7

$173.6,172.2,171.0$,

$171.5,168.4$

$236.8,239.2,231.7$

168.4

93.5

¿Deduced from adjacent temperature and pressure measurements. 
flows) a low preheater bypass of 6.8 percent was indicated. An energy balance using the "best estimate" temperature indicated an 8.7 percent bypass. Later results indicate that the low preheater outlet temperature may be high causing the energy balance to yield a value which is too large. Accordingly, the 6.8 percent bypass was judged to be the better of the two values. Temperatures were averaged utilizing the fact that there is no bypass around the high preheater so that state points 10 and 11 are the same. Boiler and condenser pressures were derived from pressure and temperature measurements around the components.

Energy balances were calculated for each of the heat exchangers. For these calculations, both geofluid and cooling water were assumed to have the properties of pure water as given in the steam tables (Reference 3 ), and the isobutane properties were taken from Reference 4. Table 2 gives the results of these calculations. The individual differences ranged between 6.4 and 8.5 percent. An overall system energy balance is given in Table 3 . The pump work was estimated from the pump characteristics knowing the flow through the pumps. The percentage difference in closure of the overall system heat balance is smaller than that of the heat balances for the individual components.

TABLE 2 - COMPONENT HEAT BALANCES USING "BEST ESTIMATE" EXPERIMENTAL VALUES

Component Heat Transfer Rate $\left(\right.$ Btu/hr $\times 10^{-7}$ )

Into Component Out of Component Average Percent Difference

$\begin{array}{lrrrr}\text { Low Preheater } & 4.004 & 4.300 & 4.109 & 7.0 \\ \text { Low Boiler } & 3.195 & 3.432 & 3.314 & 7.2 \\ \text { High Preheater } & 2.865 & 3.119 & 2.992 & 8.5 \\ \text { High Boiler } & 4.267 & 4.002 & 4.135 & 6.4 \\ \text { Condenser } & 14.960 & 13.886 & 14.430 & 7.4\end{array}$


$\begin{array}{ll}\text { Rate of Heat Transfer from Geofluid } & =42.63 \mathrm{MW} \\ \text { Power Input to Isobutane Feed Pump } & =.69 \mathrm{MW} \\ \text { Rate of Energy Flow to System } & =43.32 \mathrm{MW} \\ \text { Rate of Heat Transfer to Cooling Water } & =42.28 \mathrm{MW}\end{array}$

$$
\begin{aligned}
\text { Difference }= & 1.04 \mathrm{MW} \\
& 2.4 \%
\end{aligned}
$$

\subsection{Comparison of Experimental Data with Computer Simulation}

A further evaluation of the High Geofluid Flow Rate Test was made by simulating the plant performance on a digital computer. A model of the plant has been developed and utilized to predict plant performance (References 1 and 2). A number of conditions were input to the program, and the resultant simulation was compared to the measured temperatures, pressures, and flow rates.

Simulation of the run was accomplished by using the following boundary conditions:

1. Geofluid Flow Rate

2. Geofluid Inlet Temperature

3. Cooling Water Flow Rate

4. Flow Bypassed around Low Preheater

5. Flow Bypassed around High Preheater

6. Ambient Air Temperature

7. Ambient Air Wet Bulb Temperature

8. High Pressure Bypass Valve Opening

9. Low Pressure Bypass Valve Opening

10. Heat Exchanger Fouling for Geofluid

11. Heat Exchanger Fouling for Isobutane

12. Heat Exchanger Fouling for Cooling Water
$=978,600 \mathrm{lb} / \mathrm{hr}$

$=282.3^{\circ} \mathrm{F}$

$=6,230,000 \mathrm{lb} / \mathrm{hr}$

$=7$ percent

$=0$ percent

$=77.8^{\circ} \mathrm{F}$

$=53.0^{\circ} \mathrm{F}$

$=100$ percent

$=90$ percent

$=0.00015 \mathrm{ft}^{2} \mathrm{hr}{ }^{\circ} \mathrm{F} / \mathrm{Btu}$

$=0.00005 \mathrm{ft}^{2} \mathrm{hr} \mathrm{r}^{\circ} \mathrm{F} / \mathrm{Btu}$

$=0.00135 \mathrm{ft}^{2} \mathrm{hr} \mathrm{r}^{\circ} \mathrm{F} / \mathrm{Btu}$ 
Conditions 1 through 5 were set to be consistent with the "best estimate" data analyses (Section 2.1). Conditions 6,8 and 9 were taken from experimental data. The wet bulb temperature (condition 7) was set to give the current cooling water inlet temperature to the condenser. The experimental valve was $7.8^{\circ} \mathrm{F}$ colder than the minimum wet bulb attainable at that dry bulb temperature and therefore, is in error. The value used gives a dew point temperature of $45^{\circ} \mathrm{F}$ below the ambient temperature which seems reasonable. Conditions 10,11 and 12 , the heat exchanger fouling, represent little fouling for the geofluid and isobutane (10 percent of the design value) and 135 percent of the design value for the cooling water. This was necessary to achieve the appropriate condenser conditions.

Table 4 shows the results of this study. This table compares the values obtained in the computer simulation with the experimental values. Differences are between the average of all expected values and the simulation value. Input data is designated by placing it in parentheses in the table. Note the good agreement between the two methods. The temperatures are generally within $3^{\circ} \mathrm{F}$ except when the average experimental value is biased by one value which is far from the simulation value and the other experimental value. Flow rates are generally within 3 percent. The large deviation in pressure is in the high pressure boiler for which the experimental value appeared to be high in the previous data analysis.

\subsection{POWER GENERATION}

Detailed test data is not presently available for the time during which the plant was genrating power for distribution in the grid. The operator's data log is available, however, and it has data for the system operating as a thermal loop before and after the power generation. This data was compared with a computer simulation of power production with only the low pressure side of the turbine generating power.

Unfortunately, data such as ambient air conditions, preheater bypass flow fraction, and valve position for bypass valves is not given. These must be inferred by making the simulation match of the other actual data. First, the ambient temperature (wet and dry bulb) were changed to give the appropriate 
TABLE 4 - COMPARISON OF SIMULATION AND EXPERIMTENAL MEASUREMENTS FOR HIGH GEOFLUID FLOW TEST

State Simulation
Point
Value

\section{Geofluid}

Mass Flow Rate
$(1 \mathrm{~b} / \mathrm{hr} \times 10-6)$

$$
2,8
$$

(.9786)

$.9923, .9649$

Temperature $\left({ }^{\circ} \mathrm{F}\right)$

$\begin{array}{lrr}(282.3) & 280.1,283.2 & -- \\ 238.1 & 240.3,237.3 & 0.7 \\ 210.4 & 209.1,210.7 & -0.6 \\ 178.3 & 186.1,178.3 & 3.9 \\ 138.6 & 139.2,136.4 & -0.8\end{array}$

Cooling Water

Mass Flow Rate

$\left(1 \mathrm{~b} / \mathrm{hr} \times 10^{-6}\right)$

Temperature $\left({ }^{\circ} \mathrm{F}\right)$
40

40

41
(6.230)

(65.1)

85.9
6.230

65.1

87.4

1.5

Isobutane

Mass Flow Rate

$\left(1 \mathrm{~b} / \mathrm{hr} \times 10^{6}\right)$

Temperature $\left({ }^{\circ} \mathrm{F}\right)$
13

14

19

22

13

14

18

29

21

22

36

37

Pressure (psia)
31
24

36
.8240

.7664

.5504

.5504

97.9

175.6

170.6

170.6

231.7

231.7

--.

198.9

377.1

66.2
.9361

.8114

.5661

.5659

$97.5,97.3$

180.7

$171.0,168.4,171.5$

$172.7,113.6$

$234.7,236.8$

$242.8,231.7$

168.4

93.5

201.0

389.5

70.9

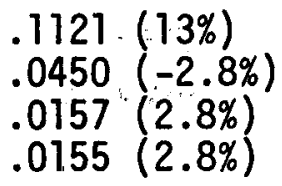

$-0.5$

5.1

0.0

2.6

4.0

5.6

0.6

2.1

12.4

4.0

( ) indicates input data to program. Heat exchanger fouling was taken as $.00005 \mathrm{hrft}^{2} \mathrm{~F} / \mathrm{Btu}$ for isobutane (10\% of design value), $0.00015 \mathrm{hrft}{ }^{\circ} \mathrm{F} / \mathrm{Btu}$ for geofluid ( $10 \%$ of design value), $.00135 \mathrm{hrft}^{2 \circ} \mathrm{F} / \mathrm{Btu}$ for cooling water (135\% of design value). 
cooling water temperature entering the condenser. Second, the high pressure turbine throttle valve (on the simulator) was closed, and the low pressure throttle valve completely opened while adjusting the high pressure bypass valve to give the correct pressure in the high pressure turbine. (The low pressure bypass valve was closed during this simulation to achieve maximum power from the low pressure turbine.) Then the preheater bypasses were adjusted to give appropriate subcooling entering the boilers.

The results of this simulation are given in Table 5. For this computer run the mass flow rates of geofluid and cooling water and heat exchanger fouling are specified as was the case with the run discussed in Section 2. The heat exchanger fouling was taken to be the same as in Section 2 because the two events occurred within 12 hours of each other. The preheater bypasses were 18 percent around the low preheater and 13 percent around the high preheater. The ambient air temperatures were changed to give the current cooling water inlet temperature, and the high pressure turbine bypass valve was adjusted to give the proper high boiler pressure.

The preheater bypasses were set to give the correct subcooling margin entering the respective boilers rather than the measured temperatures from the corresponding thermal loop test. This was done because the boiler pressure in the low boiler was allowed to change from the thermal loop value (in this case by 15 psi) when running flow through the turbines.

Under these conditions, the maximum power generated was predicted to be $1.027 \mathrm{MW}(\mathrm{e})$. This compares favorably with the reported $1 \mathrm{MW}(\mathrm{e})$ produced by the plant during this time.

\subsection{DETAILED HEAT EXCHANGER DATA}

The high pressure boiler and condenser each had a number of individual tubes instrumented to obtain tube wall temperatures. In addition, the low preheater had measurements of its intermediate temperatures. In order to verify the operation of these instruments and to deduce what is possible about performance, the condenser, having the largest number of tube wall thermocouples, was selected for analysis for the High Geofluid Flow Rate Test. 

TABLE 5 - COMPARISON OF SIMULATION AND EXPERIMENTAL MEASUREMENTS
FOR POWER PRODUCTION TEST

\begin{tabular}{|c|c|}
\hline State & Simulation \\
\hline
\end{tabular}

Geofluid

$\begin{array}{lcccr}\begin{array}{l}\text { Mass Flow Rate } \\ \left(1 \mathrm{~b} / \mathrm{hr} \times 10^{-6}\right)\end{array} & 2,8 & (0.7272) & 0.7272 & - \\ & & & & - \\ \text { Temperature }\left({ }^{\circ} \mathrm{F}\right) & 4 & (280) & 280 & 3 \\ & 5 & 241 & 245 & -3 \\ & 6 & 215 & 212 & 8 \\ & 7 & 168 & 176 & -3\end{array}$

Cooling Water

$\begin{array}{llccc}\text { Mass Flow Rate } & 40 & (6.235) & 6.235 \\ \left(1 \mathrm{~b} / \mathrm{hr} \times 10^{-6}\right) & : & & \therefore \\ & 40 & (57.0) & 57.0 & --\overline{1.6} \\ \text { Temperature }\left({ }^{\circ} \mathrm{F}\right) & 41 & 72.5 & 74.1\end{array}$

Isobutane

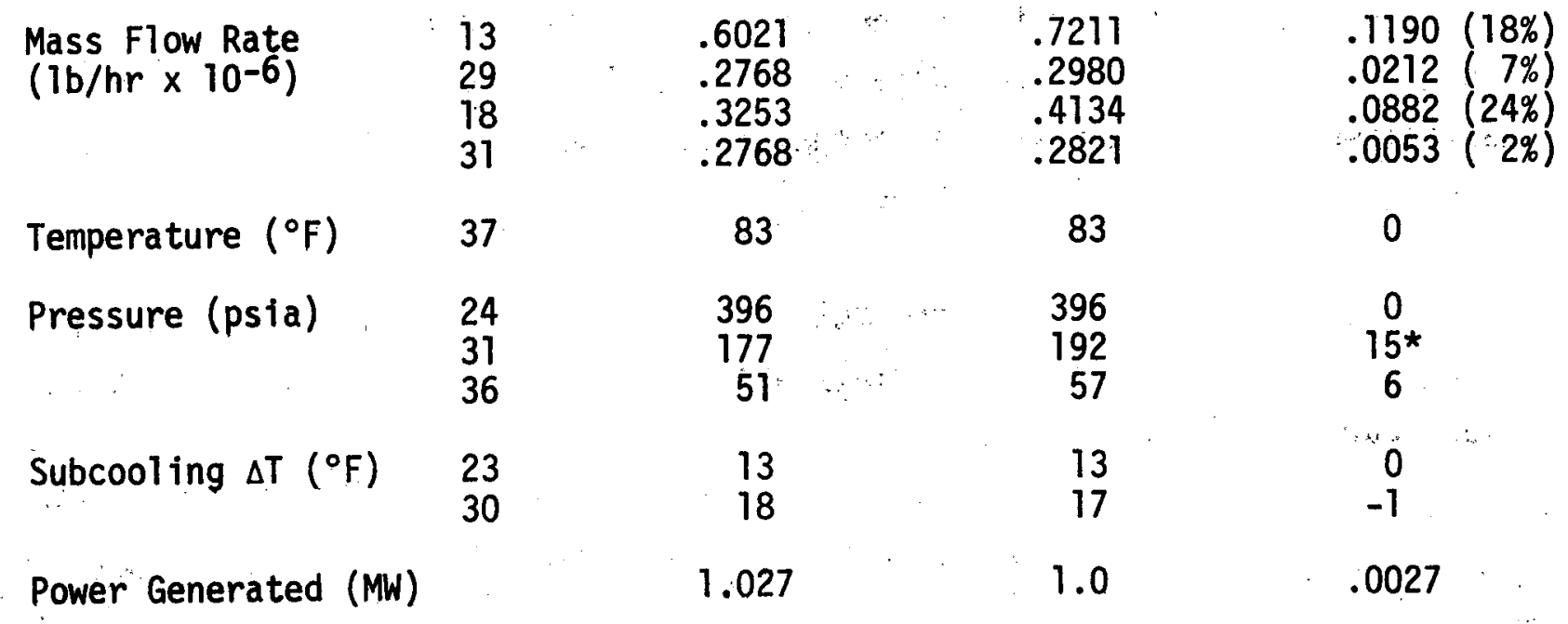

* Experimental value is for thermal loop operation while simulation is for fiow through the turbine. 
Figure 2 shows the tube bundle arrangement with the instrumented tubes marked. Tubes $A, C$ and $E$ have eight thermocouples each installed in the tube walls between 1 and 20 feet from the tubesheet on the turn around end of the heat exchangers. Tubes $B$ and $D$ each have four thermocouples installed. The bundle region below the centerline makes up the first cooling water pass and the tubes above the centerline make up the second pass. The condenser tube length is approximately 40 feet, so this means that one-half of the tube length is instrumented. Note that tubes $A, C$ and $E$ are on the vertical centerline of the bundle while $B$ and $D$ are off center.

Figure 3 shows the experimental data taken during the High Geofluid Flow Rate Test (Section 2). The closed symbols refer to the tubes which are off the vertical centerline. The distance is measured from the tubesheet on the turn around end of the exchanger. Negative distances refer to the first pass where the flow is toward the turn around (the lower part of the tube bundle) and the positive distances refer to the second pass (the top portion of the bundle). The condensing temperature $\left(98.9^{\circ} \mathrm{F}\right)$ is the value deduced from the condenser pressure in Section 2. The cooling water temperature plotted is that deduced from the inlet and outlet temperature measurements and the condenser temperature, assuming that the overall heat transfer coefficient remains constant throughout the exchanger.

The dashed lines are predictions of the wall temperatures using the condensing film heat transfer coefficient on the isobutane side (ignoring any desuperheating or subcooling effects) and forced-convection on the cooling water side. The long dashed lines assume a small amount of fouling (10 percent on each side) while the short dashed line assume the fouling indicated in Section 2.

The excursions of the temperatures on Tube $A$ are expected. Note that Tube $A$ is near the top of the bundle (and on the plane of symmetry). The vapor entering the exchanger is superheated by approximately $70^{\circ} \mathrm{F}$ and the inlet nozzle is at approximately 10 feet. This would result in high flow rates and high heat transfer coefficients in this region, and therefore, tube temperatures approaching the condensing temperature. There is no reason to expect that there is any wall temperature above the saturation temperature, however, as is indicated by the apparently bad data point at 11.6 feet. All indications are that for the conditions 


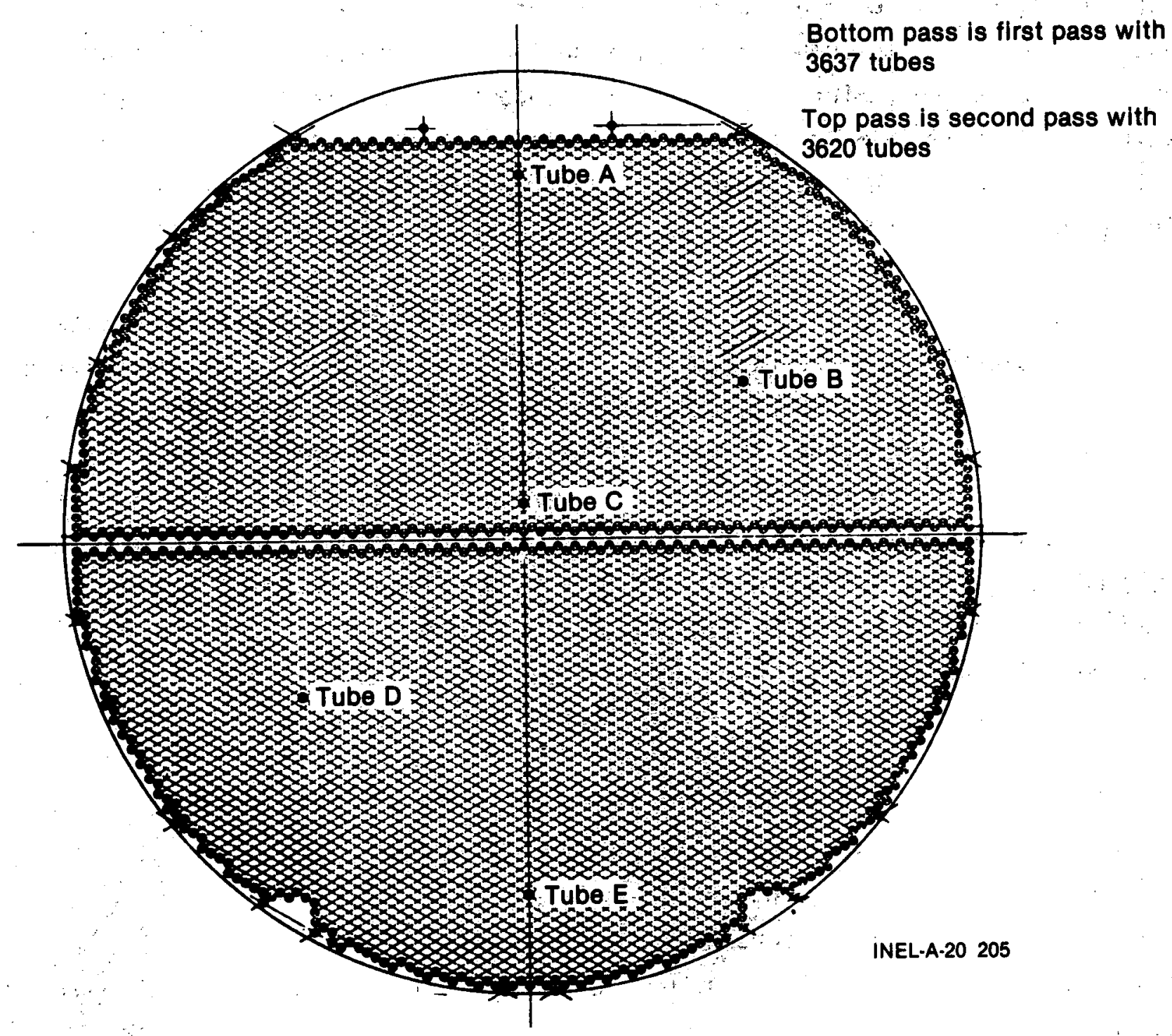

Figure 2: Location of Instrumented Tubes in the Condenser 


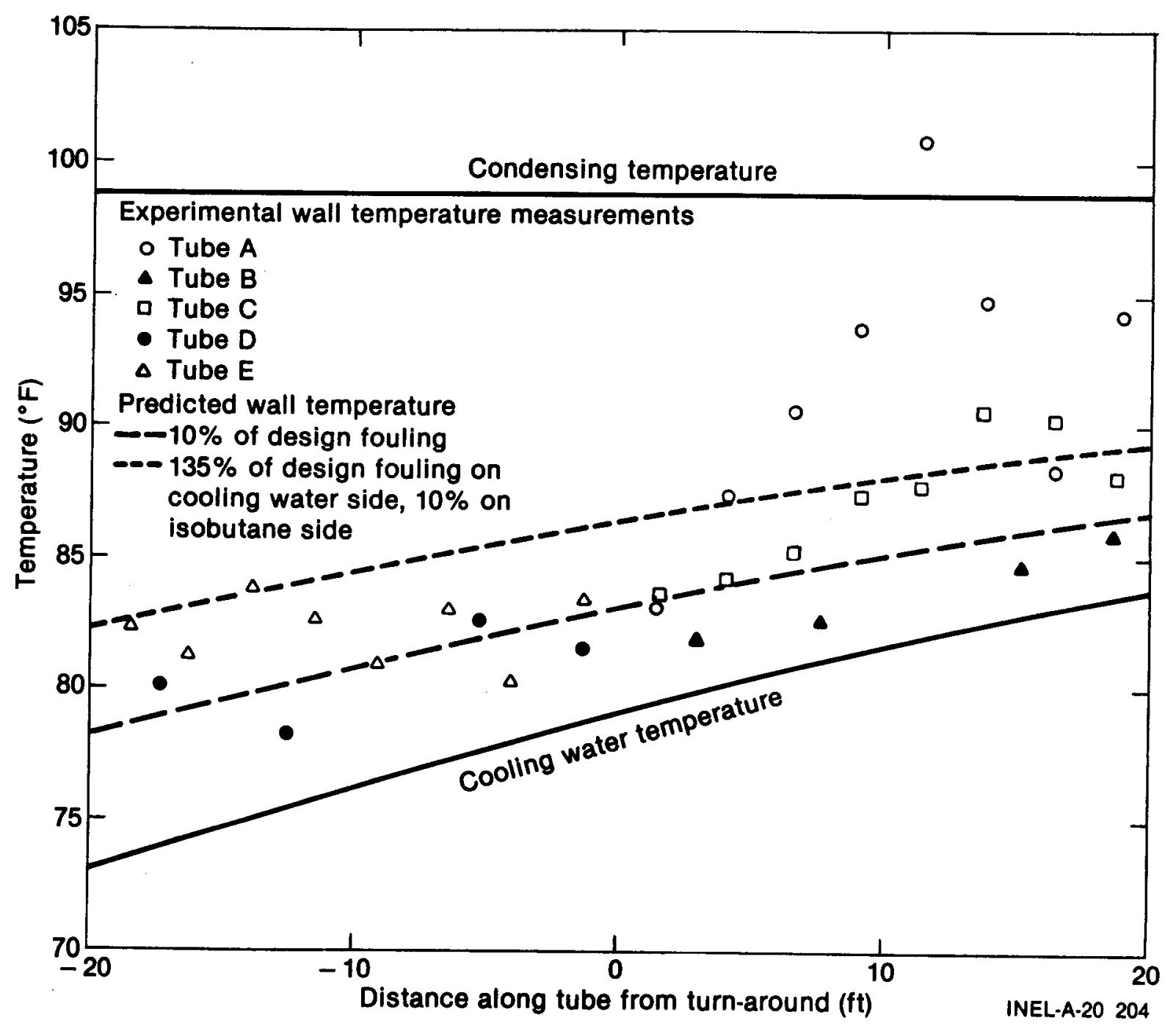

Figure 3: Condenser Tube Wall Temperatures

Compared with Experimental Data 
existing in the condenser, the desuperheating is "wet wall", and therefore, the wall temperatures should be below the condensing temperature.

Indications here are that for the condensing temperatures shown on Figure 3, the low fouling (long dashed) curve better fits the data than the high fouling case (short dashed). On the average the data falls about $0.8^{\circ} \mathrm{F}$ above the low fouling curve and $2.2^{\circ} \mathrm{F}$ below the high fouling curve if the points on Tube $A$ are eliminated. This result is very strongly a function of the assumed condensing temperature and cooling water temperatures, however. If, for example, it is assumed that the actual condensing temperature was $95^{\circ} \mathrm{F}$ instead of $98.9^{\circ} \mathrm{F}$ (perhaps accounting for some nitrogen partial pressure), and the calculations remade, Figure 4 results. Assuming that the flow around Tube $A$ at the 10 foot location is high, and the tubing is "wet wall", then the tube wall temperature will be close to the saturation temperature in that region. The three data points near the nozzle inlet on Tube $A$ then would indicate a condensing temperature closer: to $95^{\circ} \mathrm{F}$ than $98.9^{\circ} \mathrm{F}$. Under these assumptions, the high fouling curve appears to lie somewhat closer to the expected points than the low fouling curve.

These results indicate that the thermocouples in the condenser were operating and reading appropriate values. At this point, however, no definitive results are evident. Further analysis is needed to deduce the fouling in the heat exchanger, and the regimes of flow and heat transfer within the exchanger. Note that the external temperatures and energy balances are needed in conjunction with these detailed data. 


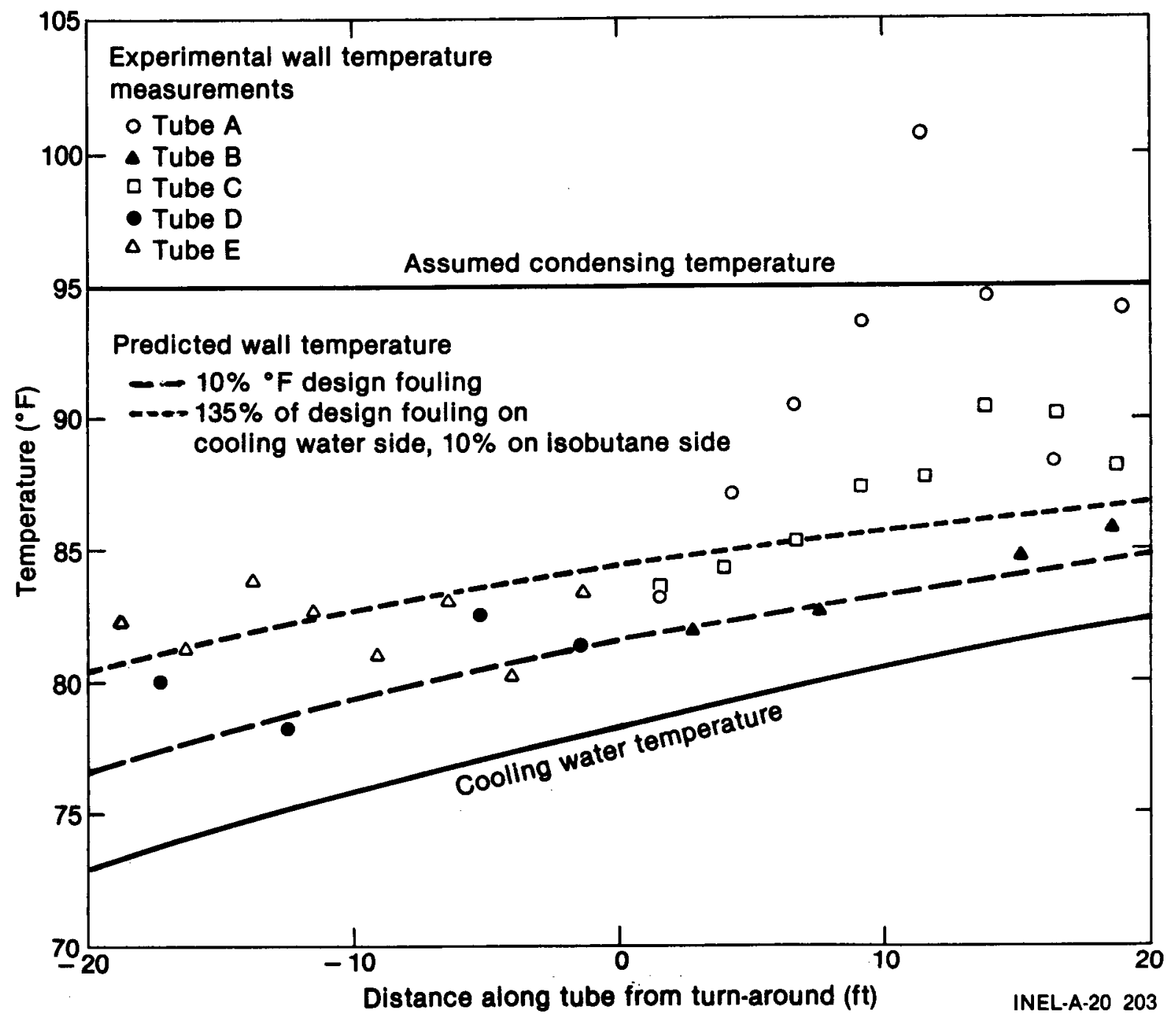

Figure 4: Condenser Tube Wall Temperature with Adjusted Condensing Temperature 


\subsection{REFERENCES}

1. C. J. Bliem, Performance and Operability Study of the Raft River $5 \mathrm{MW}(\mathrm{e})$ Pilot Geothermal Power Plant - Steady-State Behavior, PG-G-79-017, EG\&G Idaho, Inc., 1979.

2. C. J. Bliem, "Design and Off-Design Operation of a Dual-Boiling Binary Geothermal Power Plant" AIChE Symposium, Series 199, Vol. 76, Heat Transfer - Orlando, Florida, 1980.

3. K. E. Starling, Fluid Thermodynamic Properties for Light Petroleum Systems, Houston, Texas, Gulf Publishing Co., 1973.

4. Keenan, et al., Steam Tables (English Units), John Wiley \& Sons, Inc., New York, 1969. 